\title{
Dynamical Stress Analysis of Tectonic Earthquakes in Nusa Tenggara and its possible relations to the Activity of Mt. Rinjani, Indonesia
}

\author{
Bakti Sukrisna*, Kirbani, S.B**, Wahyudi**, Wiwit Suryanto**, Ade \\ Anggraini** \\ *(Department of Physics Science, Universitas Mataram, Mataram, Nusa Tenggara Barat, Indonesia \\ Email: bakti.sukrisna@gmail.com) \\ ** (Department of Physics, Universitas Gadjah Mada, Yogyakarta, Indonesia \\ Email: kirbani@mail.ugm.ac.id)
}

\begin{abstract}
Some strong earthquakes are associated with increasing of volcanic activity in near and also in far field. This research is to investigate the effect of the tectonic earthquakes in Nusa Tenggara Island area towards the October $25^{\text {th }}, 2015$ eruption of Mt. Rinjani, Indonesia. Three earthquakes occurred before the eruptions; $M_{w} 5$ Sumba earthquake on June $10^{\text {th }} 2015, M_{w} 5.8$ South of Java earthaquake July $26^{\text {th }}, 2016$ and $M_{w} 5$ South of Bali on August $6^{\text {th }}, 2015$. In theory, dynamical stress transfer can be calculated by analyzing synthetic seismogram as a waveform simulation at the volcano and the change of dynamical stress can be calculated with the finitedifference numerical method. Our result indicates that the dynamic stress value is still below the threshold value that can trigger eruptions. Simulation of three earthquakes by varying the magnitude of each earthquake shows that dynamic stress changes will surpass the threshold at $\mathrm{M}_{\mathrm{w}} \geq 7.5$. As all the earthquake that used in this study have magnitude smaller then the threshold, it can be concluded that the eruption of Mount Rinjani was triggered by internal factors, and very unlikely triggered by tyhe earthquake we investigated in this study.

Keywords - Earthquake (far-field), $\mathrm{M}_{\mathrm{w}}$ (Moment Magnitude), synthetic seismogram, finite-difference methods, Mt. Barujari
\end{abstract}

\section{INTRODUCTION}

Earthquake has been considered as a cause of volcanic activity. This argument has been observed by a lot of research through a statistical study from the data record of earthquake historical catalog and the volcano eruptions, in the local, regional or global region. That statistical research showed that there is a relation between the large tectonic earthquake $(\mathrm{Mw} \geq 7)$ and the volcano eruption with Vulcanic Explosivity Index (VEI) $\geq 2$ in 500 days temporary and $750 \mathrm{~km}$ maximum distance spatial scale [1][2][3]. The interaction between the earthquake and the volcanic activity can be physically described through the concept of stress transfer mechanism. An earthquake generated a wave source that propagates at the crust in all directions radially. The propagation of the wave caused a stress change in its distance temporary and spatially. There are three stress change models in the interaction between the earthquakes and volcanic, those are static stress change, quasi-statics, and dynamics stress change. Static stress change is a permanent stress field change (static change). Quasistatics stress change is a stress change which is related to the relaxation medium of low viscosity inside the crust and the upper mantle under large earthquake epicenter. Dynamics stress change is a transient stress change caused by the passage of seismic waves by a large earthquake [4]. The research in this paper emphasized at the dynamical transfer stress change model.

The characteristics of the dynamics stress model, its range of influence can reach thousands of kilometers depends on the size of earthquake's magnitude [5]. The value of the stress change that triggered the eruption of the volcano is about $1 \mathrm{kPa}-$ $10 \mathrm{kPa}$ [6][7]. The other factors, besides the earthquake, that caused the eruption of the volcano are earth's tides [7], climate change [8] and the collapse of glacial ice [9].

The volcano eruption mechanism that triggered by the transfer stress model with dynamical stress model can be explained as follows. The increase of pressure in the magma chamber of the volcano with a small value in $\mathrm{kPa}$ which caused by the shake of the earthquake will change the stress in the magma chamber. This could lead to the increase of bubbles of volatile gas growth and will directly cause the increase of the pressure. As the volatile gas growth increased, the increase of the pressure will be getting bigger so that overthrow the dome of the volcano. Finally, the effusive eruption occurred at the interaction between the earthquake and volcano, as in Merapi Volcano case at 2006 
[10]. The trigger effect caused the increase of the system activity, although it comes from the far-field earthquake and the small stress change, only if the volcano condition is critical [11].

The study of the volcano eruption trigger that caused by an earthquake is useful to precursor interpretation, volcano hazard mitigation in risk management disaster. The eruption of Mt. Rinjani that occurred on October $25^{\text {th }}, 2015$ is very interesting to be investigated, especially in the presence of tectonic earthquake at Nusa Tenggara that have been occurred before.

Geographically, Mt. Rinjani is located in Lombok Island, West Nusa Tenggara, Indonesia on position $8.40^{\circ} \mathrm{S}$ and $116.43^{\circ} \mathrm{E}$ with the altitude 3726 meters above sea level. Tectonically, Lombok Island is located in inner arc of Nusa Tenggara Island (The Lesser of the Sunda Islands, Fig. 2.). The inner arc of Nusa Tenggara Island is formed by subduction activity between the Indo-Australia plates under the Eurasia slab. This subduction is perpendicular one another that formed a tilt between $60^{\circ}-70^{\circ}$ with the thickness of the crust is about $20 \mathrm{~km}$ [12]. WadatiBenioff Zone is located about under $164 \mathrm{~km}$ from the Mt. Rinjani [13]. Mt. Rinjani is stratovolcanic that consist of calc-alkaline basaltic that was formed at Quartier period at Tertiary Age, volcanic and intrusive rock sediment [14].

The volcano's activity is being observed at Volcano Observation Monitor that located in Sembalun Lawang Village East Lombok District West Nusa Tenggara (Nusa Tenggara Barat (NTB)) (under the supervision of Centre for Volcanology and Geological Hazard Mitigation Indonesia).

On October $25^{\text {th }}, 2015$ at 13.00 (WITA), the activity level of Mt. Rinjani has been increased from Level I (Normal) into Level II (Alert) based on the increase of the activity of ash eruption. The seismic observation instrument record the volcanic earthquakes, tremor, eruption, explosion, low frequency, shallow volcanic (volcanic type B), depth volcanic (volcanic type A) and local tectonic and far-field tectonic in 2015 (Fig. 1).

The activity of earthquake seismicity at 2015 period varies from shallow, medium and depth earthquake so in accordance with the small, medium and large magnitude of the earthquake. The domination of the shallow earthquake is mostly in the sea and with a magnitude around the medium scale (Fig. 2).

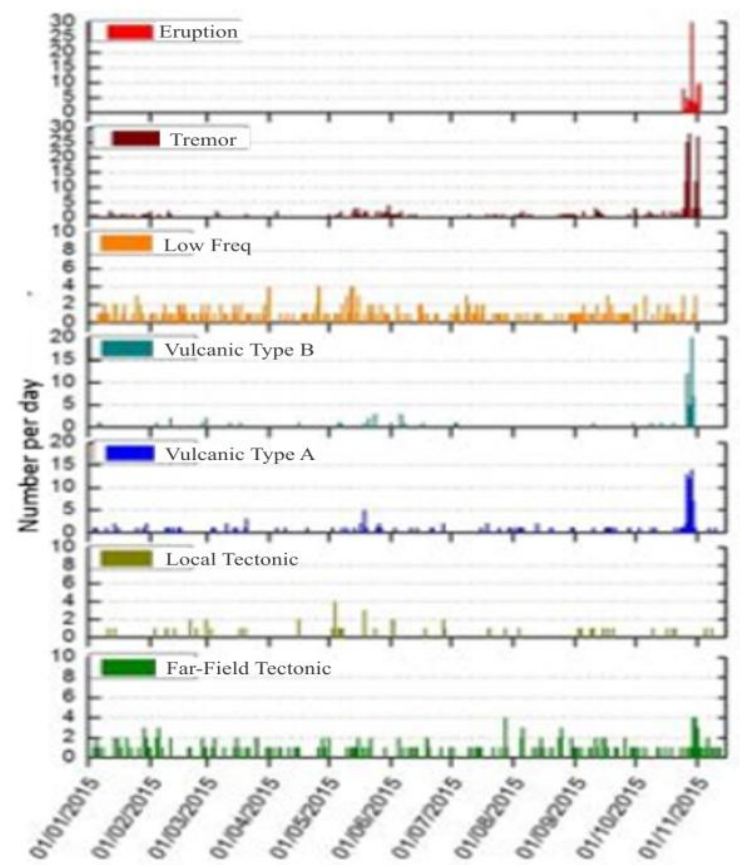

Fig. 1 Earthquake Histogram Mt. Rinjani January $1^{\text {st }}$ November $13^{\text {rd }}, 2015$ at 12:00 WITA (after CVGHM, 2015)

The purpose of this research is to find out the effect of a medium earthquake with $\geq M_{\mathrm{w}} 5$ at Nusa Tenggara Island to the activity of Mt. Rinjani, Lombok, Indonesia that occurred on October $25^{\text {th }}$, 2015. There are three reviewed earthquakes before the eruption of Mt. Rinjani, those are Sumba earthquake with magnitude scale $\mathrm{M}_{\mathrm{w}} 5$ at June $10^{\text {th }}$, 2015 , South of Java earthquake with magnitude $M_{w}$ 5.8 at July $26^{\text {th }}, 2016$ and South of Bali earthquake $\mathrm{M}_{\mathrm{w}} 5$ at August $6^{\text {th }}, 2015$ (Table 1). 


\section{METHOD}

This research had been done at Mt. Rinjani, at the coordinate $8^{\circ} 25^{\prime} \mathrm{S}$ and $116^{\circ} 28^{\prime} \mathrm{E}$ on $3726 \mathrm{~m}$ above sea level, that located in Lombok Island at the coordinate $7^{\circ}-12^{\circ} \mathrm{S}$ until $112^{\circ}-125.5^{\circ} \mathrm{E}$ (Fig. 2).

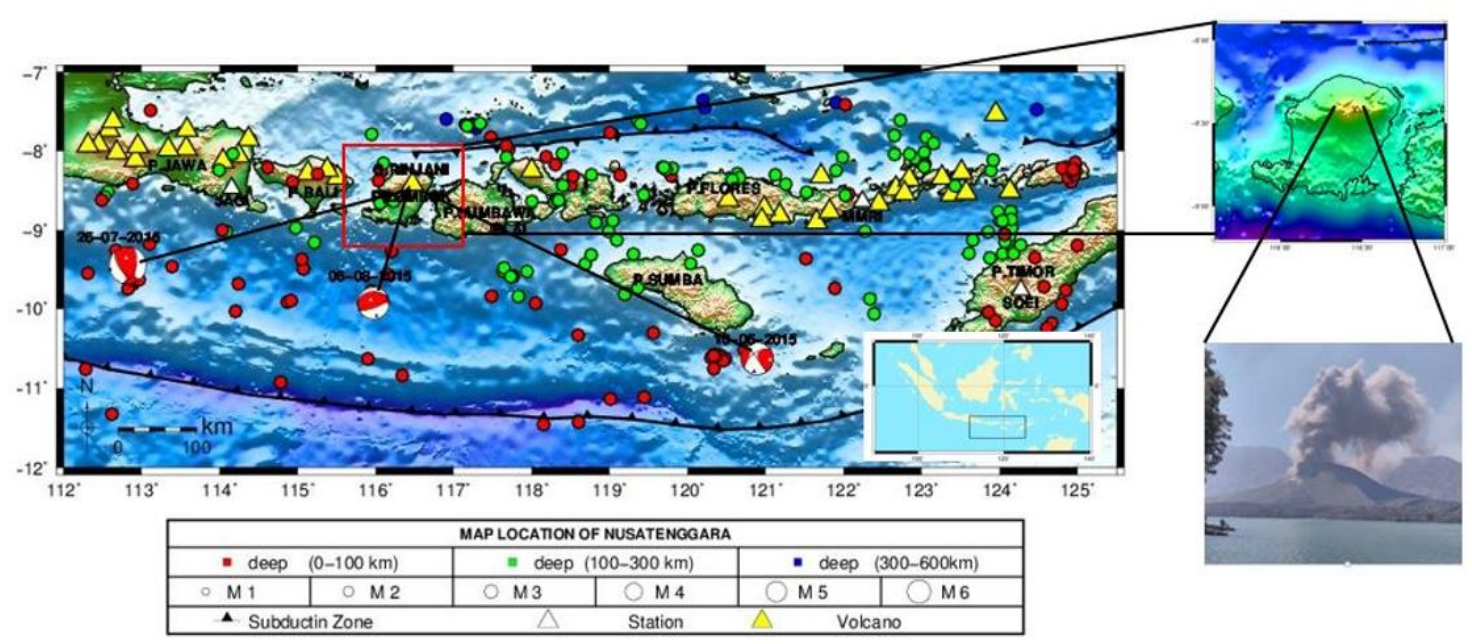

Fig 2. Map of the Location of the Research and Earthquake Focal Mechanism Catalogue Sumba June $10^{\text {th }} 2015$ Mw5, earthquake South of Java July $26^{\text {th }}, 2015$, Mw5,8 and Earthquake South of Bali August $6^{\text {th }}, 2015$, Mw5 and The Central Eruption of Rinjani Complex Vocano at Mt. Barujari inside The Caldera on October $25^{\text {th }} 2015$ (after CVMBG)

The calculation of dynamic stress changes in the magma systems of Mt. Barujari in the Mt. Rinjani complex resulted from earthquake using the catalogue data focal mechanism with seismogram record at GFZ Germany's network station. The seismogram data are taken from Sumbawa's earthquake occurred on June $10^{\text {th }}$, 2015, South of Java's earthquake at July $26^{\text {th }}, 2015$ and South of Bali's earthquake at August $6^{\text {th }}, 2015$ (Table 1).

Table 1. Focal Mechanism Earthquake Catalogue Data (after GFZ GEOFON German)

\begin{tabular}{|c|c|c|c|c|c|c|}
\hline Location & \multicolumn{2}{|c|}{ Sumba, Indonesia } & \multicolumn{2}{|c|}{ South of Java, Indonesia } & \multicolumn{2}{|c|}{$\begin{array}{l}\text { South of Bali, } \\
\text { Indonesia }\end{array}$} \\
\hline Time & \multicolumn{2}{|c|}{$\begin{array}{l}\text { Jume 10", 2015, } \\
\text { UTC 22:01:32.58 }\end{array}$} & \multicolumn{2}{|c|}{$\begin{array}{l}\text { July } 26^{\circ}, 2015 \text {, } \\
\text { UTC 07: 05:09.06 }\end{array}$} & \multicolumn{2}{|c|}{$\begin{array}{l}\text { August } 6^{\natural}, 2015 \text {, } \\
\text { UTC 05:05:49.85 }\end{array}$} \\
\hline$\overline{P o s i t i o n}$ & \multicolumn{2}{|c|}{$\begin{array}{ll}\text { Latitude } & -10.56 \\
\text { Longitude } & 120.87\end{array}$} & \multicolumn{2}{|c|}{$\begin{array}{ll}\text { Latitude } & -9.23 \\
\text { Longitude } & 112.70\end{array}$} & \multicolumn{2}{|c|}{$\begin{array}{ll}\text { Latitude } & -9.85 \\
\text { Longitude } & 115.94\end{array}$} \\
\hline Depth & \multicolumn{2}{|c|}{$58 \mathrm{~km}$} & \multicolumn{2}{|c|}{$62 \mathrm{~km}$} & \multicolumn{2}{|c|}{$61 \mathrm{~km}$} \\
\hline Magnitude & \multicolumn{2}{|c|}{ Mw 5.0} & \multicolumn{2}{|c|}{ Mw 5.8} & \multicolumn{2}{|c|}{ Mw 5.0} \\
\hline Mo & \multicolumn{2}{|c|}{$4.20 \mathrm{E}+16 \mathrm{Nm}$} & \multicolumn{2}{|c|}{$6.40 \mathrm{E}+17$} & \multicolumn{2}{|c|}{$3.60 \mathrm{E}+16 \mathrm{Nm}$} \\
\hline Focal Mechanism & NP1 & $\mathrm{N} 22$ & NP1 & NP2 & $\mathrm{NP1}$ & $\mathrm{NP} 2$ \\
\hline Strike & 330 & 128 & 75 & 245 & 17 & 227 \\
\hline Dip & 78 & 43 & 61 & 30 & 3 & $\overline{45}$ \\
\hline Ralice & -132 & 159 & 95 & 81 & 252 & -17 \\
\hline Moment Tensor & \multicolumn{2}{|c|}{$10 \mathrm{E}+16 \mathrm{Nm}$} & \multicolumn{2}{|c|}{$10 \mathrm{E}+17 \mathrm{Nm}$} & \multicolumn{2}{|c|}{$10 \mathrm{E}+16 \mathrm{Nm}$} \\
\hline Mfxn & \multicolumn{2}{|c|}{-1.41} & \multicolumn{2}{|c|}{3.53} & \multicolumn{2}{|c|}{2.92} \\
\hline Mitt & \multicolumn{2}{|c|}{-2.32} & \multicolumn{2}{|c|}{2.36} & \multicolumn{2}{|c|}{-2.80} \\
\hline MipD & \multicolumn{2}{|c|}{3.73} & \multicolumn{2}{|c|}{-5.89} & \multicolumn{2}{|c|}{-0.12} \\
\hline Mrts & \multicolumn{2}{|c|}{1.33} & \multicolumn{2}{|c|}{2.44} & \multicolumn{2}{|c|}{1.83} \\
\hline Mrs & \multicolumn{2}{|c|}{-2.29} & \multicolumn{2}{|c|}{0.28} & \multicolumn{2}{|c|}{0.37} \\
\hline Mtp & \multicolumn{2}{|c|}{0.62} & & & & .12 \\
\hline Double Couple & & & & & & ) \\
\hline
\end{tabular}


The dynamical stress analysis had been done with making seismogram pressure model at magma system Mt. Barujari. The first step that needed is making a synthetic seismogram at recording station with parameters from the focal mechanism, the earth velocity model (AK-135 F) [15], depth source, the distance of epicenter with the record station, window time, frequency sampling and the depth of recording station. The next step, the convolution is done in the frequency range between Green function and the parameter source function above. The synthetic seismogram is made with the program code Qseis that had been developed by Wang [16].

In addition, the synthetic seismogram results will be confirmed with velocity seismogram that recorded with Geofon GFZ Germany at Jagi and Plai station (see http://www.gfz-posdam.de/geofon). The calibration is done with the quantitative ways using misfit criteria method [17], based on the timefrequency representation of seismogram obtained as the continuous wavelet transform with the analyzing Morlet wavelet. The misfit criteria include timefrequency envelope and phase misfits. After matching between synthetic and recording seismogram, with the same ways, we made the synthetic seismogram in the magma volcano systems with the same source function and Green function parameter.

Furthermore, the dynamical stress change calculated by using pressure calculation approach at some point volume in magma volcano system. The pressure approach calculated from volumetric strain multiplied with Bulk' constants [10]. Volume point, that reviewed, considered as particles shift from synthetic seismogram. The volumetric strain and the Bulk' constants written in mathematical equations as mentioned in equation (1) and (2), while the pressure at some point volume mentioned in equation (3).

$$
\begin{aligned}
\frac{\Delta V}{V_{o}} & =\varepsilon_{11}+\varepsilon_{22}+\varepsilon_{33}=\frac{\partial_{u_{1}}}{\partial_{x_{1}}}+\frac{\partial_{u_{2}}}{\partial_{x_{2}}}+\frac{\partial_{u_{3}}}{\partial_{x_{3}}} \\
K & =\lambda+\frac{2}{3} \mu \\
P & =\frac{\Delta V}{V_{o}} \kappa
\end{aligned}
$$

This research is using Bulk' constant that calculated from Lame $\lambda=0.1045 \mathrm{GPa}$ and $\mu=1.02$ GPa parameters so that Bulk' constants $\kappa$ will be valued $0.7845 \mathrm{GPa}[10]$. While, the Bulk' constants multiplied with volumetric strain at a point of Mt. Barujari magma chamber is located. The dynamical stress values change is calculated using the finitedifferent numerical methods.

\section{RESULTS AND DISCUSSION}

Dynamical stress change that caused by an earthquake to the volcano magma system was calculated at $3 \mathrm{~km}$ depth, which was calculated by equation (3), that's volumetric strain multiplied with Bulk' constants. Based on the calculation, dynamical stress change can be seen at the maximum amplitude from peak to peak pressure synthetic seismogram (Fig. 3, $4 \& 5$ ). The results from three earthquakes which reviewed from dynamical stress change in the magma systems of Mt. Barujari can be seen in Table (2).

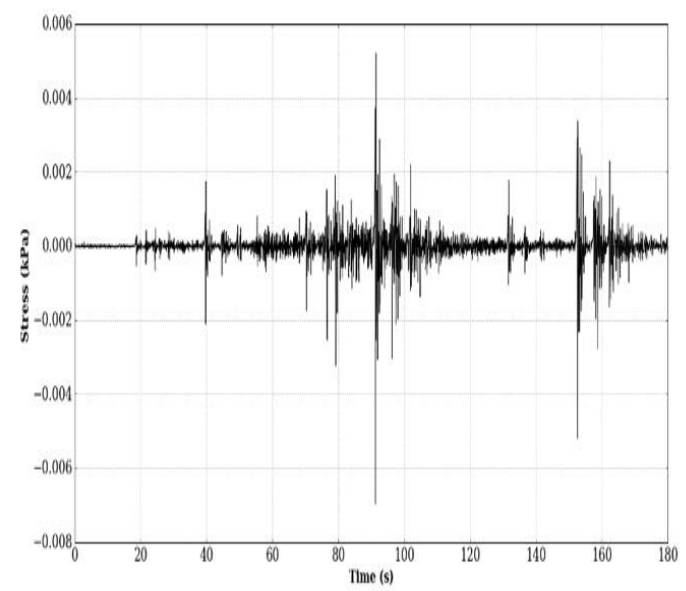

Fig. 3. Dynamical Stress Change Caused by Earthquake from June $10^{\text {th }} 2015$ at Mt. Barujari in Rinjani Complex in $3 \mathrm{~km}$ Depth

The dynamical stress change modeling result on three earthquakes that reviewed showed as follows:

First, the acquisition of dynamical stress from Sumba's earthquake at June $10^{\text {th }}, 2015$, at 58 $\mathrm{km}$ depth with magnitude $\mathrm{M}_{\mathrm{w}} 5$, calculated in $3 \mathrm{~km}$ depth under magma system of Mt. Barujari with $544.92 \mathrm{~km}$ distance from epicenter was $0.012 \mathrm{kPa}$ (Table 2). The difference of time between the earthquake and eruption was about 4 months.

Second, the South of Java earthquake at July $26^{\text {th }}, 2015$ at $62 \mathrm{~km}$ depth and magnitude $\mathrm{M}_{\mathrm{w}}$ 5.8 with $417.97 \mathrm{~km}$ epicenter distance from the volcano and $3 \mathrm{~km}$ depth of magma chamber. Its dynamical stress is $0.125 \mathrm{kPa}$ and the difference between the earthquake and eruption was 3 months.

Third, the South of Bali earthquake at August $6^{\text {th }}, 2015$ with $61 \mathrm{~km}$ depth and magnitude $\mathrm{M}_{\mathrm{w}}$ 5, epicenter distance $169.29 \mathrm{~km}$ away from the volcano and $3 \mathrm{~km}$ bag magma depth with $0.2 \mathrm{kPa}$ dynamical stress change. The difference between the earthquake and the eruption was 2 months. 


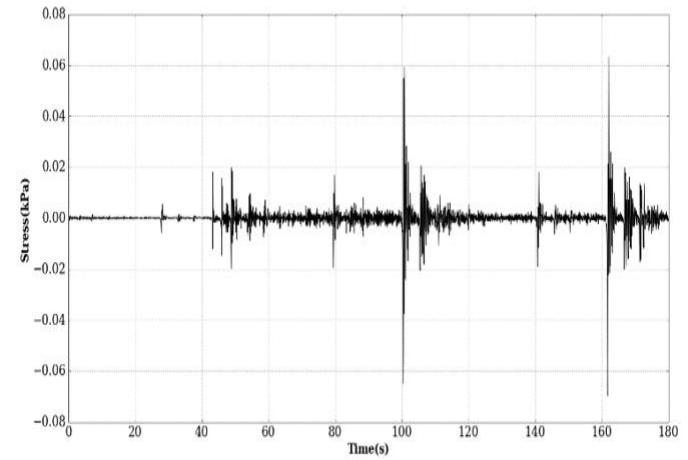

Fig. 4. Dynamical Stress Change Caused by Earthquake at July $26^{\text {th }}, 2015$ at Mt. Barujari in Rinjani Complex at $3 \mathrm{~km}$ depth under the peak

Earthquake, that had been reviewed, is included with far-field effect from the seismic wave with a medium magnitude between $5 \leq \mathrm{Mw} \leq 7$.

Results showed that the stress change values wasn't significant as a volcano eruption trigger, if we compare it to the threshold eruption, according to Walter (6). However, the activity of Mt. Rinjani kept increasing from October $25^{\text {th }}, 2015$ until four months later. The speculation of interpretation stated that eruption of Mt. Rinjani is caused by an internal factor.

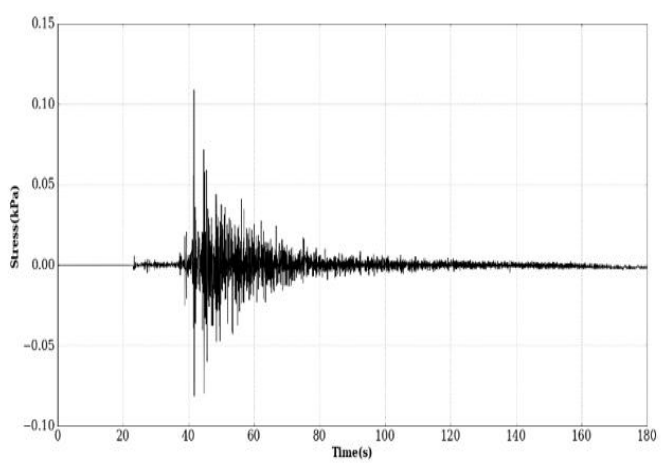

Fig. 5. Dynamical Stress Change Caused by earthquake at August $6^{\text {th }}, 2015$ at Mt. Barujari in Rinjani Complex in $3 \mathrm{~km}$ depth under the peak

The eruption mechanism, because of external factor, much affected by the amount of the amplitude, the distance of epicenter from the earthquake to the volcano, the orientation of fault sources of the earthquake and the condition of the volcano, whether it's in crisis or not [18].

The critical condition is determined from the inside of magma, including magma's composition and their physical and chemical properties. The influx of low-density magma, from the bottom to the upper position, push the magma that located in the upper for rising to the surface and the volcano's vent will be opened because of the insistence so that the eruption occurred.
Table 2. The Dynamical Stress Change Calculation Results

\begin{tabular}{|c|c|c|c|c|c|c|c|c|c|c|}
\hline \multirow{3}{*}{ Date } & \multirow{3}{*}{. $\mathrm{sr}$} & \multirow{3}{*}{$\begin{array}{l}\text { Source } \\
\text { Depth } \\
\text { km }\end{array}$} & \multirow{2}{*}{\multicolumn{2}{|c|}{ Epicenter }} & \multirow{2}{*}{\multicolumn{2}{|c|}{ WIE Banjari }} & Epicentral & Arimoth & Jhgma & \multirow{3}{*}{$\begin{array}{l}\text { Stress } \\
(\mathrm{APa})\end{array}$} \\
\hline & & & & & & & \multirow[t]{2}{*}{ (km) } & \multirow{2}{*}{$\left(^{0}\right)$} & \multirow[t]{2}{*}{$(\mathrm{km})$} & \\
\hline & & & Lat $\left({ }^{\circ}\right)$ & $\operatorname{Lan}\left({ }^{0}\right)$ & $\operatorname{Lat}\left({ }^{\circ}\right)$ & $\operatorname{Lon}\left({ }^{\circ}\right)$ & & & & \\
\hline Sumba & \multirow{2}{*}{5} & \multirow{2}{*}{58} & \multirow{2}{*}{-10.56} & \multirow{2}{*}{120.87} & \multirow{2}{*}{-8.4} & \multirow{2}{*}{116.41} & \multirow{2}{*}{544.91} & \multirow{2}{*}{87.38} & \multirow{2}{*}{2} & \multirow{2}{*}{0.012} \\
\hline 10,62015 & & & & & & & & & & \\
\hline Jara & \multirow[b]{2}{*}{5.8} & \multirow[b]{2}{*}{62} & \multirow[b]{2}{*}{-9.23} & \multirow[b]{2}{*}{112.7} & \multirow[b]{2}{*}{-8.4} & \multirow[b]{2}{*}{116.41} & \multirow[b]{2}{*}{417.97} & \multirow[b]{2}{*}{89} & \multirow[b]{2}{*}{2} & \multirow[b]{2}{*}{0.125} \\
\hline \begin{tabular}{|c|}
$26,07 / 201$ \\
5
\end{tabular} & & & & & & & & & & \\
\hline Bali & \multirow{2}{*}{5} & \multirow{2}{*}{61} & \multirow{2}{*}{-9.88} & \multirow{2}{*}{115.93} & \multirow{2}{*}{-8.4} & \multirow{2}{*}{116.41} & \multirow{2}{*}{169.29} & \multirow{2}{*}{88.22} & \multirow{2}{*}{2} & \multirow{2}{*}{0.2} \\
\hline 6882015 & & & & & & & & & & \\
\hline
\end{tabular}

By changing the variation of magnitude values with a fixed distance at the epicenter of three earthquakes, we calculated the dynamical stress change with simulation test. The results showed that the earthquake above $\geq M_{w} 7$ (Table 3) influenced the dynamical stress change, because of exceeding the threshold as a trigger in volcano's eruption.

Table 3. The Result of Dynamical Stress Change Calculation

\begin{tabular}{|c|c|c|c|}
\hline \multirow[t]{2}{*}{ Magnitude Mw } & $\begin{array}{c}\text { Earthquake } \\
\text { June 10 } 0^{\text {th }}, 2015 \\
\end{array}$ & $\begin{array}{c}\text { Earthquake } \\
\text { July } 26^{\text {th }}, 2015 \\
\end{array}$ & $\begin{array}{c}\text { Earthquake } \\
\text { August } 6^{\text {th }}, 2015 \\
\end{array}$ \\
\hline & $\Delta$ Stress $(\mathrm{kPa})$ & $\Delta$ Stress $(\mathrm{kPa})$ & $\Delta$ Stress $(\mathrm{kPa})$ \\
\hline 5 & 0.012 & 0.004 & - \\
\hline 5.5 & 0.07 & 0.02 & 0.35 \\
\hline 6 & 0.14 & 0.125 & 0.82 \\
\hline 6.5 & 0.5 & 1.95 & 4.4 \\
\hline 7 & 3 & 3.9 & 25 \\
\hline 7.5 & 15 & 20.5 & 145 \\
\hline 8 & 90 & 125 & 790 \\
\hline 8.5 & 470 & 690 & 4800 \\
\hline 9 & 3000 & 3800 & 24000 \\
\hline 9.5 & 15000 & 21500 & 138000 \\
\hline
\end{tabular}

The Earthquake simulation has been made with varying the amount of magnitude with the fixed epicenter's distance at the dynamical stress change calculation from three earthquakes. The results showed can be seen at the Table (3). The purpose of the simulation is to know at which amount of amplitude with fixed dynamical stress change $\geq 10$ $\mathrm{kPa}$.

\section{CONCLUSION}

Normally, the interaction research between the tectonic earthquake and the volcano eruption is observed by seeing the earthquake before the eruption. In this research, we observed the tectonic earthquake effect to the volcano eruption phenomena.

The three earthquakes around Nusa Tenggara those have been observed are far-field tectonic earthquakes with a medium magnitude which expected to affect the eruption activity at Mt. Barujari in the Rinjani Complex. We used the stress transfer mechanism from earthquake to the volcano in studying with dynamical stress analysis model. Before the eruption, the earthquake occurred for 2 to 4 months. 
The dynamical stress measurements from three earthquakes reviewed in this research have shown that the dynamical stress change in the volcano magma system in the $3 \mathrm{~km}$ depth have the values less than the eruption's threshold. The stress change value that does not prove the Mt. Barujari's eruption in the Rinjani complex, caused by the tectonic far-field earthquake. Whereas, the simulation test from three earthquakes reviewed with magnitude variation and fixed epicentral distance showed that an earthquake with $\geq \mathrm{M}_{\mathrm{w}} 7.5$ magnitude, the dynamical stress change exceeded the threshold. The important thing in this research is the eruption trigger at Mt. Barujari, Lombok caused by from internal factor, while the external trigger is the large earthquakes around the research site.

\section{ACKNOWLEDGEMENTS}

We would like to thank Geophysics Laboratory, Faculty of Math and Natural Sciences, Universitas Gadjah Mada, Indonesia for supporting this study. Special recognition goes to Geofon GFZ German, BMKG dan CVGHM that supporting data.

\section{REFERENCES}

[1]. A. T. Linde and I. S. Sacks, "Triggering of volcanic eruptions," NATURE, vol. 395, no. October, pp. 272-275, 1998.

[2]. M. Manga and E. Brodsky, "Seismic Triggering of Eruptions in the Far Field: Volcanoes and Geysers," Annual Reviews of Earth and Planetary Sciences 34, 263291, 2006.

[3]. S. Eggert and T. R. Walter, "Volcanic activity before and after large tectonic earthquakes: Observations and statistical significance," Tectonophysics, vol. 471, no. 1-2, pp. 14-26, Jun. 2009.

[4]. A. Harris, "Introduction to special section : Stress triggers, stress shadows, and implications for seismic hazard," Journal of Geophysics Research, vol. 103, pp. 24,34724,358, October 10, 1998.

[5]. D. P. Hill and S. G. Prejean, Treatise on Geophysics. Elsevier, 2007.

[6]. R. S. Stein, "The role of stress transfer in earthquake occurrence," NATURE, vol. 402, no. December, pp. 605-609, 1999.

[7]. S. Tanaka, M. Ohtake, and H. Sato, "Tidal triggering of earthquakes in Japan related to the regional tectonic stress," Earth Planets Space, 56 (5)., pp. 511-515, 2004

[8]. B. Mcguire, C. R. Firth, and A. Pullen, "Correlation between rate of sea level and frequency of explosive volcanism in the Mediterranean of sea-level change and," NATURE, Vol 389 October, 1997.

[9]. Pagli, C. and Sigmundsson, F., Will present day glacier retreat increase volcanic activity ? Stress induced by recent glacier retreat and its effect on magmatism at the Vatnajokull ice cap, Iceland.Geophysical Research Letters, 35 (9). Art.No L09304. ISSN 0094-8276, 2008.

[10]. T. R. Walter, "Volcanic activity influenced by tectonic earthquakes: Static and dynamic stress triggering at Mt. Merapi," Geophysical Research Letters, 34, L05304, doi:10.1029/2006GL028710, 2007.

[11]. C. Newhall, D. P. Hill, F. Pollitz, and C. Newhall, "Earthquake-Volcano Interactions," Physics Today, Vol 55, no. 11, p 41-47, November, 2002.

[12]. R. Curray, G. G. Shor, W. Raitt, and M. Henry, "Seismic Refraction and Reflection Studies of Crustal Structure of the Eastern Sunda and Western Banda Arcs Singleship," Journal of Geophysics Research, vol. 82, no. 17, pp. 2479-2489, 1977.

[13]. H. Rachmat, M. F. Rosana, A. D. Wirakusumah, and G. A. Jabbar, "Petrogenesis of Rinjani Post-1257Caldera-Forming-Eruption Lava Flows," Indonesian Journal on Geoscience, vol 3, no. 2, pp. 107-126, August, 2016.

[14]. A. Nasution, A. Takada, D. Widarto, L. Hutasoit, and T. Bandung, "Rinjani and Propok Volcanics as a Heat Sources of Geothermal Prospects from Eastern Lombok, Indonesia," Jurnal Geoaplika, vol. 5, pp. 1-10, 2010.

[15]. B. L. N. Kennett, E. R. Engdah, and R. Buland, "Constraints on seismic velocities in the Earth from traveltimes," Geophysics Journal International. 122, pp. 108-124, 1995.

[16]. S. Society, "A Simple Orthonormalization Method for Stable and Efficient Computation of Green , s Functions,"Belletin of the Seismological Society of America, 89, no. 3, pp. 733-741, June, 1999.

[17]. J. Kristek, P. Moczo, and S. M. Day, "Misfit Criteria for Quantitative Comparison of Seismograms," Belletin of the Seismological Society of America, vol. 96, no. 5, pp. 1836-1850, 2006.

[18]. D. D. Donne, A. J. L. Harris, M. Ripepe, and R. Wright, "Earthquake-induced thermal anomalies at active volcanoes," Geology, vol. 38, no. 9, pp. 771-774, 2010. 